\title{
PORTABILITY OF CARTOGRAPHIC SYMBOLS LIBRARY FOR OPEN STANDARDS
}

\author{
F. R. Ferreira ${ }^{1 *}$, C. E. M. Mota $^{2}$, A. G. S. Barcellos ${ }^{2}$ \\ ${ }^{1}$ Geological Survey of Brazil - CPRM, Geological Infrastructure Board, Institutional Information Department, Geoscience \\ Infrastructure Management, São Paulo, Brazil - flavia.ferreira@cprm.gov.br \\ ${ }^{2}$ Geological Survey of Brazil - CPRM, Geological Infrastructure Board, Institutional Information Department, Data Science \\ Research Group, Rio de Janeiro, Brazil - (carlos.mota, alvaro.barcellos)@ cprm.gov.br
}

KEY WORDS: Symbolization, Cartography, Palaeontology, OGC, Open Data, Data Infrastructure.

\begin{abstract}
:
The Geological Survey of Brazil has a library of palaeontology symbols to use in geological mapping works, currently in bitmap format and adapted for ESRI platform. This type of representation has presented anti-aliasing problems when reduced, in addition to not being suitable for map presentation on the web, according to OGC (Open Geospatial Consortium) specifications. This work presents a reproducible method in any symbol library type. The method consists of converting the symbol library to open-source format, resulting an OpenType font file, which can be installed on any operating system and view each symbol font in any software that has this functionality, such as a GIS (Geographic Information Systems) software. The need to develop font construction technique is due to improving typographic quality of cartographic representations and making library compatible with main GIS softwares. Those 61 pictorial palaeontology symbols were converted, one by one, to SVG (Scalable Vector Graphics) format. We imported each symbol as a glyph in FontForge font editor. Major computer platforms use OpenType format due to its wide availability and typographic flexibility, including provisions to deal with diverse characteristics of internationally symbolic alphabet systems. There is even the possibility of symbols standardizing in the UTF-8 alphabet system, an issue for the scientific community to study. The advantage of using the SVG format is its size, a compact text file, and has an excellent compression factor. In addition, version-control repositories, like GitHub, can store SVG files, which would facilitate content management. The adopted method proved to be applicable to any cartographic symbols library with good results. Rendering tests on different platforms (web or desktop) showed no noticeable differences. One of the most important aspects of the method presented in this work was to make cartographic symbols library public and open-source for use by the geoscientific community, regardless whether an open-source or proprietary platform is used, and so, the Geological Survey of Brazil will be able to distribute geological symbology patterns, according to Open Data definition.
\end{abstract}

\section{INTRODUCTION}

Symbolization, which is the definition of cartographic symbols and conventions that will represent geographic information on a map or chart, is, along with generalization, one of the cognitive transformations to which geographic information will be subjected. Cognitive transformations come from geographic information, so they can represent the real world cartographically (Menezes \& Fernandes, 2013).

Symbols can represent any geospatial data. Such symbols are classified by their geometry, which can be defined in three graphical primitive classes: points, lines and areas (Cromley, 1992; Robinson et al., 1995).

Technical manuals, such as the $\mathrm{T}$ 34-700 manual for cartographic conventions of the General Staff of the Brazilian Armed Forces (DSG, 2002), and the standards for the International Map of the World to the Millionth Scale, define the symbology used in the base maps of the Brazilian systematic mapping (IBGE, 1993).

In Brazilian thematic cartography, unlike base maps, there is no standardization of conventions due to the variability of representable phenomena. Thus, the thematic symbols creation, their distribution and visualization are exclusive responsibility of the author of the cartographic document, and must always be included in the map legend, as well as, when necessary, the elaboration of descriptive tables that allow the map interpretation by a layman (Menezes \& Fernandes, 2013).

The US Geological Survey (USGS), together with the Federal Geographic Data Committee (FGDC), created a guideline entitled FGDC Digital Cartographic Standard for Geologic Map Symbolization (FGDC, 2006) that provides a single national standard for digital cartographic representation of geological map elements. For the same purpose, the British Geological Survey created a guideline entitled Cartographic Standard Geological Symbol Index (Mawer, 2002). There is variability in the symbols and geological phenomena representation between the two documents.

The Geological Survey of Brazil - CPRM developed a library of cartographic symbols to serve as a guideline in the Brazilian geological mappings. In this document, there is specific symbology for geological, geophysical, paleontology, features, sedimentary structures and geochronology.

\footnotetext{
* Corresponding author
} 


\section{GEOLOGY SYMBOLIZATION EMPLOYED BY THE GEOLOGICAL SURVEY OF BRAZIL}

The symbolization employed by the Geological Survey of Brazil - CPRM uses symbols classified as pictorial, geometric and associative. Visual variables used connote a qualitative visual differentiation such as shape, direction, color and pattern.

Pictorial symbols are characterized by a direct connection with the type of phenomenon represented. They can be simple, complex or stylized, and must always be highly effective in communication (Menezes \& Fernandes, 2013). Figure 1 shows an example of a pictorial point symbol, which represents an amphibious fossil.

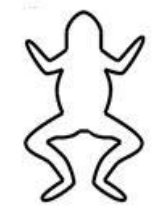

Figure 1. Amphibian fossil symbol.

Geometric symbols have no shape association with the represented phenomenon, using geometric shapes such as circle, triangle, rectangle, star, among others. Figure 2 shows an example of a geometric point symbol, which represents a mineral deposit.

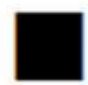

Figure 2. Mineral deposit symbol.

Associative symbols employ a combination of geometric and pictorial to produce identifiable symbols. Figure 3 shows an example of an associative point symbol, which represents igneous layering.

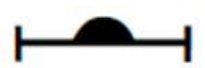

Figure 3. Igneous layering symbol.

The paleontology symbolization adopted by CPRM comes from the USGS symbol library (FGDC, 2006). These symbols are currently in bitmap format adapted for the ESRI platform, and have presented anti-aliasing problems when scaled to a larger size, and in addition, they are not in the proper standard for the presentation of maps on the web, according to specifications of the OGC (Open Geospatial Consortium).

To adapt paleontology symbolization to the OGC standards, this work proposes the conversion of the symbol library to Scalable Vector Graphics format (SVG), an open-source format for scalable vector designs, defined by the World Wide Web Consortium (W3C). Figure 4 shows norms and standards adopted in this work.
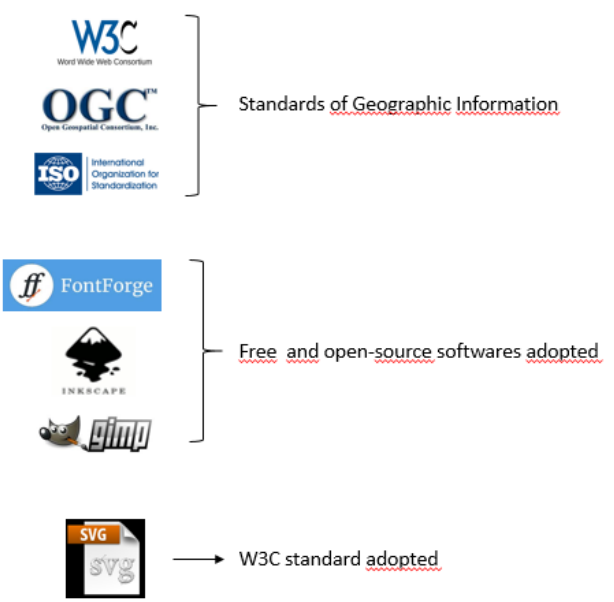

Figure 4. Standards and open-source technologies adopted.

\section{CONVERSION OF SYMBOLS TO THE SVG FORMAT}

This method can be used in any type of symbol library. The symbols, which in CPRM are almost exclusively in the ESRI ${ }^{\circledR}$ standard, must be converted, one by one, to the SVG format. This step can be done using free software such as Gimp. This type of representation has presented problems of anti-aliasing when adapted to larger scales, in addition to not being suitable for the presentation of maps on the web, according to OGC specifications. FontForge font editor imports symbols, in SVG format, as a specific type of design (glyphs) and associates each of them with a character code. Editing work on the drawing may be necessary for its perfect visualization in graphic software. This is easily accomplished in the Inkscape software. With the font file, compiled in the FontForge software, containing the entire symbol library, it is possible to install it on the Windows ${ }^{\circledR}$ (or any other) operating system and view each of the symbol fonts in any GIS software. Figure 5 shows the workflow diagram.

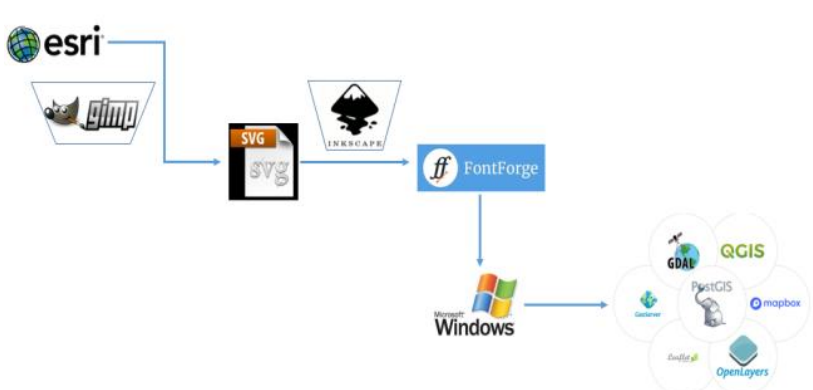

Figure 5. Workflow diagram.

Glyph (symbol) was different from original drawing, observed in FontForge, such as, for example, the glyph corresponding to the symbol called "trilobite", appeared as a drawing completely filled in black, without showing internal drawing features, Figure 6. Analyzing drawing characteristics in FontForge construction viewer, polylines built symbol outlines, as shown in Figure 7. 


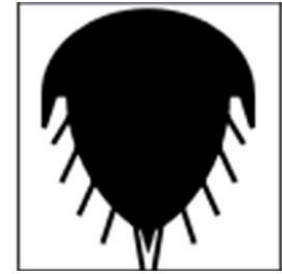

Figure 6. Trilobite fossil symbol displayed in FontForge font editor.

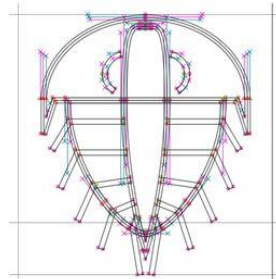

Figure 7. Trilobite fossil symbol in FontForge construction viewer.

Glyph design properties did not need to be changed, but we had to convert glyph outlines into polygons instead of polylines. We used "convert contour into path" function in Inkscape software. After this edition, we imported glyph into FontForge software, with a perfect visualization of all its features, Figure 8 . The symbol outline as a polygon shape is shown in Figure 9.

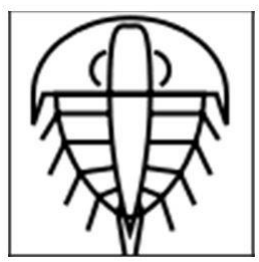

Figure 8. Visualization of the symbol after editing in Inkscape.

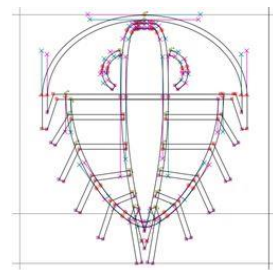

Figure 9. Visualization of the symbol outline as a polygon.

The set of glyphs was compiled in an OpenType font file as shown in Figure 10. The OpenType standard is used on major computer platforms due to its wide availability and typographic flexibility, including provisions to deal with the diverse characteristics of all writing systems in the world (ISO14496/22). The need to develop the font construction technique is due to improving the typographic quality of cartographic representations and making the library compatible with the main GIS softwares.

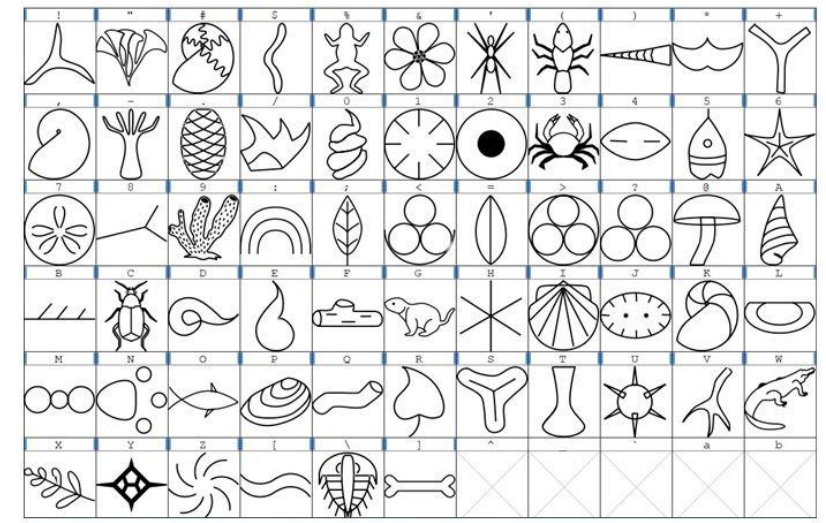

Figure 10. Glyphs compiled in the font file format.

\section{CONCLUSIONS}

SVG format uses vector graphics consisting of geometric primitives such as points, lines, curves and polygons, derived from mathematical expressions and therefore do not lose definition when their size is increased. This scalability is the biggest advantage of using SVG format to represent cartographic symbols instead of using the raster format.

SVG format is a text file and has an excellent compression factor, that is another advantage of its use. In addition, the contents can be kept in repositories with version control, like GitHub, which facilitates the management of the content.

This method proved to be applicable to any library of cartographic symbols with good results. Rendering tests on different platforms (web or desktop) showed no noticeable differences. The typographic quality of cartographic representations improved and the library became compatible with the main GIS softwares.

One of the most important aspects of the method presented in this work was to make the cartographic symbols library of CPRM public and open-source for use by the geoscientific community, regardless of whether an open-source or proprietary platform is used, so CPRM may distribute geologic symbol standards, according to the Open Data definition.

\section{REFERENCES}

DSG - Diretoria de Serviço Geográfico. 2002. Manual Técnico de Convenções Cartográficas T-34-700, $1^{\text {a }}$ e $2^{\mathrm{a}}$ Partes. Brasília: DSG.

Cromley, R. G. 1992: Digital cartography. Englewood Cliffis: Prentice Hall, 317 p.

FEDERAL GEOGRAPHIC DATA COMMITTEE (prepared for the Federal Geographic Data Committee by the U.S. Geological Survey), 2006, FGDC Digital Cartographic Standard for Geologic Map Symbolization: Reston, Va., Federal Geographic Data Committee Document Number FGDC-STD-013-2006, 290 p., 2 plates. ngmdb.usgs.gov/fgdc_gds/geolsymstd/fgdcgeolsym-all.pdf (2 June 2020). 
IBGE - INSTITUTO BRASILEIRO DE GEOGRAFIA E ESTATÍSTICA. 1993. Manual de normas, especificações e procedimentos técnicos para a Carta Internacional do Mundo ao Milionésimo - CIM 1:1.000.000. Rio de Janeiro.

INTERNATIONAL ORGANIZATION FOR STANDARDIZATION. ISO/IEC 14496-22:2019 Information technology - Coding of audio-visual objects - Part 22: Open Font Format.

Mawer, C H. 2002.Cartographic standard geological symbol index. Version 3. British Geological Survey Research Report, RR/01/01. 49pp. ISBN $085272 \quad 402$ nora.nerc.ac.uk/id/eprint/3221/1/RR01001 (2 June 2020).

Menezes, P.M.L.; Fernandes, M. C. 2013: Roteiro de Cartografia. São Paulo: Oficina de Textos, 288.

Robinson, A.H.; Morrison, J.L.; Muehrcke, P.C.; Kimmerling, A.J.; Guptil, S.C. 1995: Elements of cartography. 6. ed. New York: John Wiley \& Sons, 544 p. 